\title{
The Classification of Micrococci and Staphylococci Based on their DNA Base Composition and Adansonian Analysis
}

\author{
By S. ROSYPAL, ALENA ROSYPALOVÁ AND J. HOŘEJŠ \\ Department of Microbiology, Biochemistry and Numerical Mathematics, \\ Faculty of Science, J. E. Purkyně University, Brno, Czechoslovakia
}

(Received 6 January 1966)

\begin{abstract}
SUMMARY
Species of the genus Staphylococcus have a guanine+cytosine (GC) content in DNA within the range $30 \cdot 7-36 \cdot 4$ moles $\%$. All the Gram-positive cocci so far designated as micrococci and sarcinas which produce acid from glucose when grown under anaerobic or aerobic conditions and have a GC content in DNA within this range should be also classified as Staphylococcus. On the other hand species of the genus Micrococcus have a GC content in DNA within the range $66 \cdot 3-73 \cdot 3 \%$. All the Gram-positive cocci hitherto designated as sarcinas and staphylococci which do not produce acid from glucose under aerobic or anaerobic conditions or only aerobically and which have a GC content in DNA within this range, should be also classified as Micrococcus. The range of GC content as outlined is approximate; it will be made more accurate (perhaps a little broader) when more data are available on the DNA base composition of the species belonging to the family Micrococcaceae.

On the basis of their DNA base composition the strains belonging to the genus Micrococcus are divided into three groups: group $1(70 \cdot 8-$ $73 \cdot 3$ moles \% GC); group $2(67 \cdot 5-69.5$ moles \% GC); group $3(66 \cdot 3-$ 67.0 moles \% GC). Similarly the strains belonging to the genus Staphylococcus have been divided into three groups: group $\mathbf{5}(\mathbf{3 6} \cdot 4$ moles $\% \mathrm{GC})$; group $6(33 \cdot 3-34 \cdot 2$ moles \% GC); group $7(30 \cdot 7-32 \cdot 7$ moles \% GC). Strains within each group are believed to be phylogenetically related. When subjected to Adansonian analysis, the strains of the individual groups were clustered into subgroups. Each subgroup comprised the strains with approximately the same DNA base composition and a high \% similarity of physiological and biochemical characters. Strains clustered into subgroups are believed to be genetically closely related, some may be identical. The following subgroups are suggested: micrococcus subgroups $1 \mathrm{a}, 1 \mathrm{~b}, 2 \mathrm{a}, 2 \mathrm{~b}$, 2c, 3a, 3 b; staphylococcus subgroups 5a, 6a, 7a. Arabic numerals refer to the designation of the group.

The classification of micrococci presented in this paper is substantially the same as that of Baird-Parker (1965). The authors are of the same opinion as Baird-Parker (1965) that Micrococcus denitrificans should be reclassified with the Gram-negative genera.
\end{abstract}

\section{INTRODUCTION}

The study of phylogenetic relationships among bacterial species made on the basis of their DNA base composition leads to conclusive results only when it concerns species of the same morphology, i.e. usually the species belonging to the 
same family. Even when two morphologically different bacteria belonging to different families have the same DNA base composition, it cannot be concluded that they are phylogenetically related. Their morphological difference suggests that they are phylogenetically distant. In this case similarity in DNA base composition does not express the fact that their DNA has a similar sequence of bases. On the other hand, organisms with the same morphology and DNA base composition are usually phylogenetically related. However, their phylogenetic relationship is of different degree and they may, therefore, differ from one another more or less physiologically and biochemically. Only the organisms that are known to have the same DNA base composition and high degree of similarity in physiological and biochemical characters may be considered to be closely related genetically. It is, therefore, believed that before separating a set of organisms into species it would be better to classify them into groups, each comprising the strains not differing in DNA base composition and having a high degree of similarity of physiological and biochemical characters. On the basis of these considerations we have attempted to classify bacteria originally included in the genera Micrococcus, Staphylococcus and Sarcina. The DNA base composition in these cocci has been recently determined by Rosypalová, Boháček \& Rosypal (1966 a, b). Rosypal, Boháček \& Rosypalová (1966) and Rosypal \& Rosypalová (1966). The strains with the same DNA base composition have been grouped together and then subjected to Adansonian analysis according to Sneath (1957) in order to cluster the strains which are similar not only as to DNA base composition, but also biochemically and physiologically. Such strains are believed to be closely related genetically.

\section{METHODS}

The strains studied were obtained from the Czechoslovak Collection of Microorganisms (CCM) and are listed in Table 1 under the name received by the CCM from other collections and under the new name assigned to them in the CCM. The base composition of DNA preparations from these strains were determined from their denaturation temperature $\left(T_{m}\right)$ by Rosypalová, Boháček \& Rosypal $(1966 a, b)$, Rosypal et al. (1966), Rosypal \& Rosypalová (1966).

Each bacterial strain was tested for physiological and biochemical characters. For each strain, the following 67 properties were used in the computer analysis: grouping of organisms (packets, clumps); colonies on glucose yeast-extract agar (rough, smooth); pigment production on glucose yeast-extract agar (yellow, violet, pink pigments); dissociation in pigmentation; hydrolysis of starch, casein and gelatin; reduction of nitrates and nitrites; production of catalase, urease and lipase; sensitivity to chloramphenicol, chlortetracycline, terramycin, tyrothricin, nystatin, bacitracin and lysozyme; hydrolysis of aesculin and salicin; methyl red test; effects. on milk; Gram-reaction; growth on Simmon's citrate agar; production of acid from carbohydrates (glucose, sucrose, galactose, fructose, mannose, lactose, xylose, glycerol, adonitol, sorbitol, mannitol); oxidation of carbohydrates in phosphate buffer at $\mathrm{pH} 7$ (acetate, lactate, glycerol, mannitol, dulcitol, sorbitol, arabinose, xylose, rhamnose, glucose, galactose, fructose, sucrose, maltose, lactose, starch); oxidation of amino acids in phosphate buffer at pH 7 (glycine, alanine, threonine, leucine, lysine, histidine, arginine, proline, tryptophan, asparagine, glutamic acid). 
Data concerning these tests and the methods used are given in papers by Kocur \& Martinec (1962), Rosypal, Kocur \& Hoď́k (1963), Rosypal \& Kocur (1963), Rosypalová \& Rosypal (1966).

The results of each test were scored as positive $(+)$ or negative $(-)$. Similarity $(S)$ values for pairs of strains were calculated according to the formula (Sneath, 1957):

Number in

Table 2 and

Fig. 2

1
2
3
4
5
6
7
8
9
10
11
12
13
14
15
16
17
18
19
20
21
22
23
24
25
26
27
28
29
30
31
32
33
34
35

Table 1. List of strains studied

Number of the strain and the name under which it was received by the CCM

Staphylococcus flavocyaneus NCrc, 7011

Micrococcus sp. L.A. 9.1*

M. flavocyaneus*

M. flavocyaneus L.A. 8.2*

M. flavocyaneus L.A. 8.1*

M. flavus ATCC, 400

$M$. sodonensis ATCC, 11880

Sarcina subflava ATCC, 381

S. marginata IFo, 3066

S. flava isolated by Kocur

S. variabilis IFO, 3067

S. citrea $\dagger$

S. pelagia sio

Micrococcus luteus АТCC, 398

Staphylococcus afermentans NCTC, 2665

Sarcina lutea isolated by Kocur

$S$. lutea isolated by Kocur

Micrococcus lysodeikticus 53-20‡

Sarcina aurantiaca ATCC, 146

Micrococcus cyaneus L.A. 1.1*

Staphylococcus roseus NCTC, 7520

Micrococcus roseus $\$$

M. rubens AтcC, 412

Sarcina erythromyxa АТс, 187

$S$. ventriculi CRIPP

Micrococcus denitrificans NCIB, 8944

$M$. conglomeratus ATCC, 401

$M$. candidus мсІв, 8610

$M$. citreus $\mathrm{NCIB}, 8611$

Staphylococcus lactis NCTC, 7564

Sarcina oliva $\dagger$

Micrococcus infimus sio

$M$. euryhalis sio

$M$. varians м 3\||

$M$. cerolyticus ATcc, 12559

Staphylococcus aureus NCTC, 8511

S. aureus lysogenic derivative of NCTC, 8511
Number of strain and its new name given by the CCM
Micrococcus luteus 247
$M$. luteus $\mathbf{8 5 2}$
M. luteus 622
M. luteus 851
M. luteus 853
M. luteus 210
M. luteus 144
M. luteus $\mathbf{5 5 9}$
M. luteus 265
M. luteus 309
M. luteus 266
M. luteus 248
M. luteus 331
M. luteus 810
M. luteus 855
M. luteus $\mathbf{5 2 3}$
M. luteus 310
M. luteus 1335
M. luteus 686
M. luteus 856
Micrococcus roseus 146
$M$. roseus 905
$M$. roseus 633
M. roseus 706
M. conglomeratus 208
M. denitrificans 982
M. conglomeratus 547
M. varians 1044
$M$. varians 1046
M. varians 884
$M$. varians 250
M. varians 313
$M$. varians 315
M. varians 529
M. varians 901

* From Dr C. B. van Niel, Hopkins Marine Station, California, U.S.A.; $\uparrow$ Institute of Hygiene, Perugia, Italy; $\ddagger$ From Dr H. B. Naylor, Laboratory of Bacteriology, Cornell University, Ithaca, New York, U.S.A.; \& From Dr S. Aaronson, Haskins Laboratory, New York, U.S.A.; || From Dr F. J. Simpson, Prairie Regional Laboratory, Saskatoon, Canada.

IH, Institute of Hygiene, Warsaw, Poland; NCIB, National Collection of Industrial Bacteria, Torry Research Station, Aberdeen, Scotland; ATCC, American Type Culture Collection, Rockville, Md., U.S.A.; NCTC, National Collection of 'Type Cultures, London, England; CRIPP, Central Research Institute of Plant Production, Prague-Ruzyně, ČSSR; SIO, Scripps Institution of Oceanography, La Jolla, California, U.S.A.; IFO, Institute for Fermentation, Osaka, Japan; CCM, Czechoslovak Collection of Microorganisms, J. E. Purkyně University, Brno, ČSR. 
$S=n_{s} / n_{s}+n_{d}$ where $n_{s}$ is the number of features positive for both organisms and $n_{d}$ is the number of features positive for one but not the other organism. The Mean Similarity expressed as 'Triangle Mean' $\Delta S$ was also calculated (see Sneath, 1957). The MINSK electronic digital computer was employed. Copies of the program may be obtained from the authors.

\section{RESULTS}

Taking into consideration that the values of moles $\%$ GC content in DNA determined in individual strains from the denaturation temperature $T_{m}$, are reproducible within the limits of $\pm 1 \%$, the whole set of strains can be divided into seven groups (see Fig. 1). In the sequels moles \% GC means moles $\%$ guanine + cytosine in the given DNA preparation. Differences in moles \% GC values within these groups are not considered to be significant. The borderlines between the respective groups are only approximate and may be modified as soon as new data on DNA base composition in micrococci and staphylococci are available. However, no substantial changes are to be expected. The following classification into groups is suggested:

Group 1, strains with a GC content within the range 70.8-73.3 moles $\%$.

Group 2, strains with a GC content within the range $67 \cdot 5-69 \cdot 5$ moles $\%$.

Group 3, strains with a GC content within the range $65 \cdot 8-67 \cdot 0$ moles $\%$. As stated in the Discussion, the species Micrococcus denitrificans is not included in this group. The range of GC is therefore $66 \cdot 3-67 \cdot 0$ moles $\%$.

Group 4 is for the time being represented by only one strain with a GC content $\mathbf{5 4 . 2}$ moles \% GC.

Group 5 is also represented by one strain with a GC content $36 \cdot 4$ moles $\%$ GC.

Group 6, strains with a GC content within the range $33 \cdot 3-34 \cdot 2$ moles $\%$.

Group 7, strains with a GC content within the range 30.7-31.1 moles \%. This range is broader $(\mathbf{3 0} \cdot \mathbf{7}-\mathbf{3 2} \cdot \mathbf{7}$ moles $\%$ GC) when we take into account the data by Silvestri \& Hill (1965).

When subjected to Adansonian analysis, the strains of individual groups were clustered into subgroups. Each subgroup comprised the strains with approximately the same DNA base composition and a high \% of similarities in physiological and biochemical characters (see Table 2, Fig. 2). The intra-group and inter-group similarity values ( $\Delta S$ or Triangle Mean) are given in Table 3. The success of the clustering is indicated by the intra-group $S$ values. The subgroups were obtained at approximately $70 \% \Delta S$ (see Table 3 ).

Group 1 is divided into subgroups 1 a $(\Delta S=72 \%)$ and $1 \mathrm{~b}(\Delta S=73 \%)$. The inter-group $S$ value between these subgroups equals $59 \% S$.

Group 2 is formed of subgroups $2 \mathrm{a}(\Delta S=67 \%), 2 \mathrm{~b}$ and $2 \mathrm{c}$; subgroups $2 \mathrm{~b}$ and $2 \mathrm{c}$ are represented by only one strain each. Subgroup $\mathbf{2 b}$ is very similar to subgroups $1 \mathrm{a}$ and $1 \mathrm{~b}$, though having a different moles \% GC content.

Group 3 is formed of subgroups $\mathbf{3 a}, \mathbf{3 b}$ and $\mathbf{3 c}$, each represented by one strain. Subgroups $3 \mathrm{a}$ and $3 \mathrm{~b}$ have great similarity to subgroup $1 \mathrm{a}$, although differing from it by their DNA GC contents.

Groups 4, 5 and 6 have each only one subgroup: $4 \mathrm{a}, 5 \mathrm{a}$ and $6 \mathrm{a}(\Delta S=71 \%)$ and are quite dissimilar from all the above-mentioned groups and subgroups. There is a high percentage of similarity between subgroups 4 a and 5 a (inter-group $S$ 


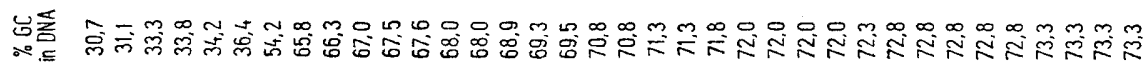
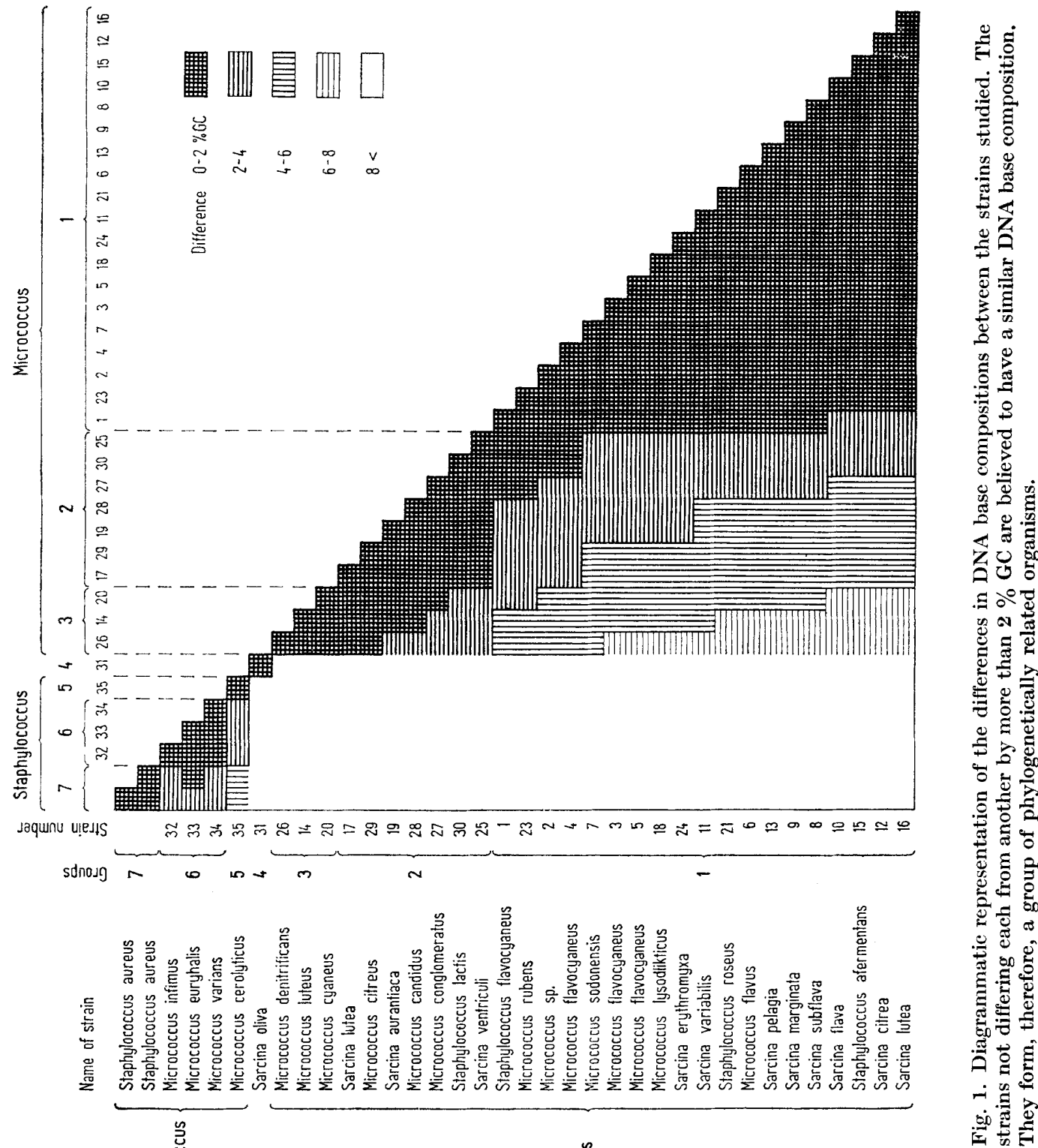

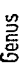

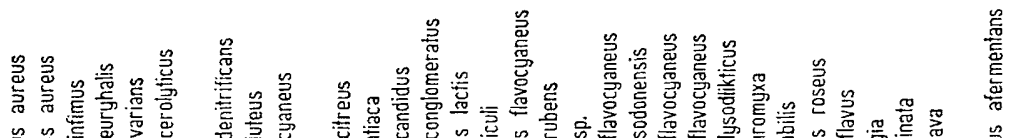

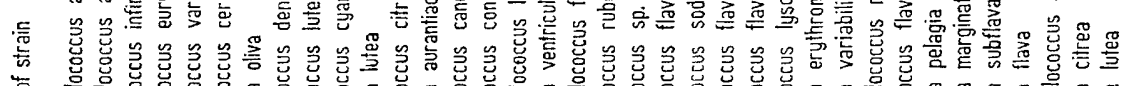

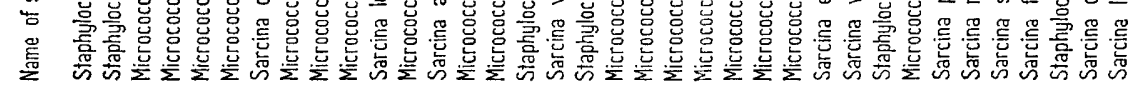

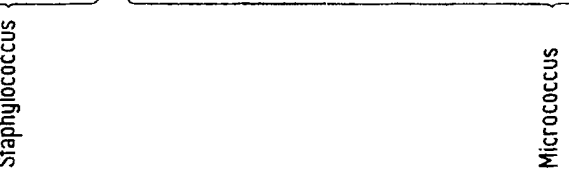



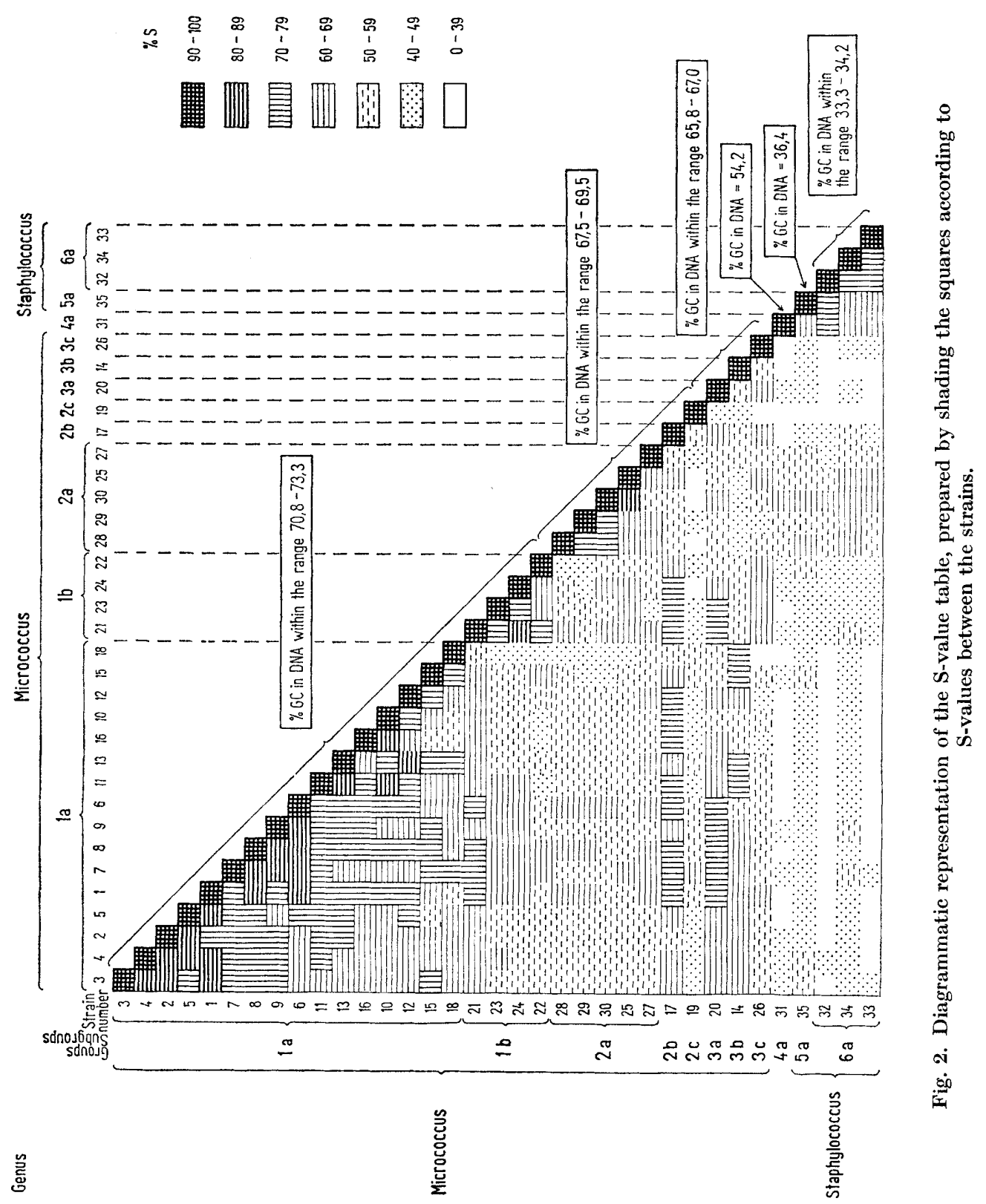


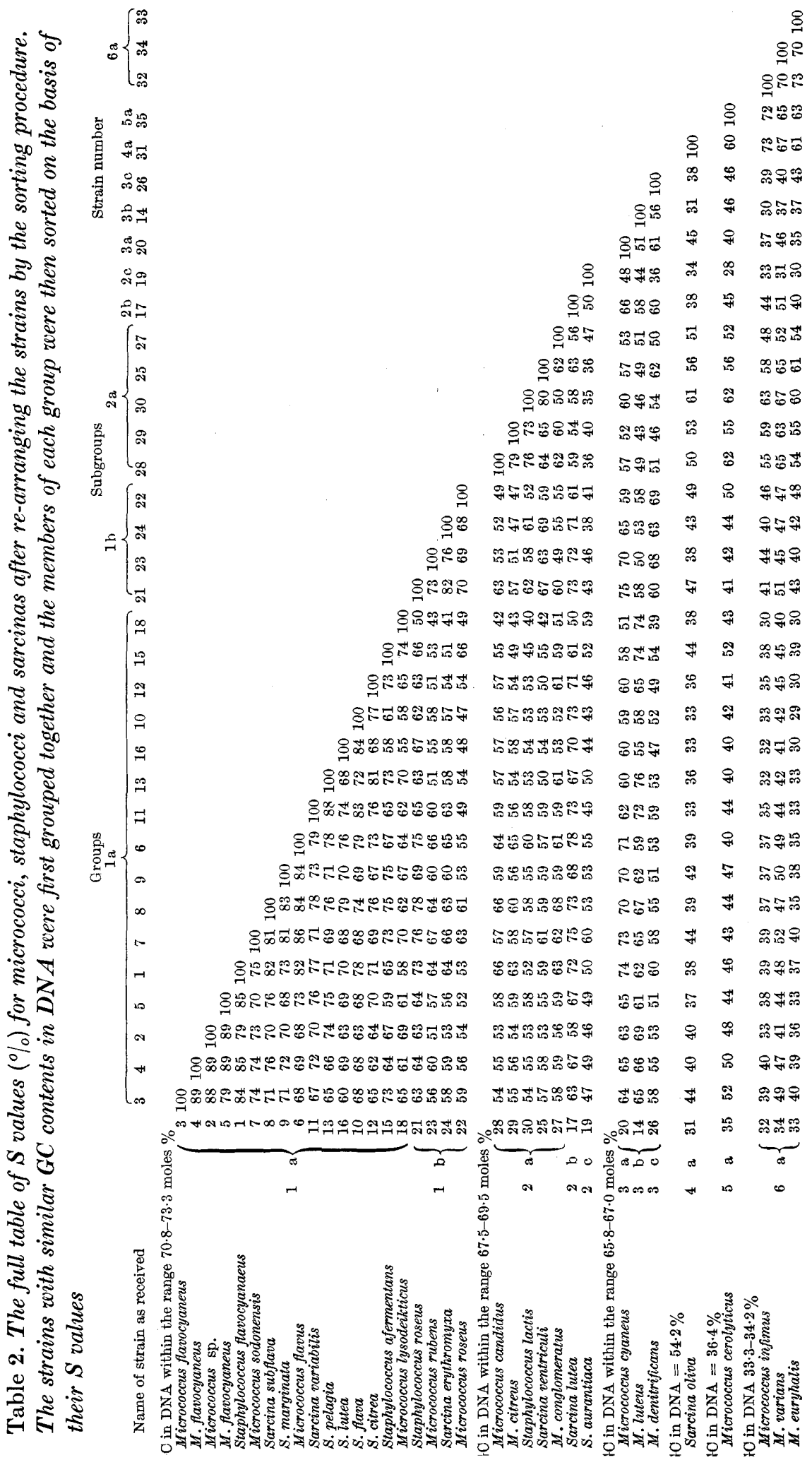


value $=60 \%$ ), $5 \mathrm{a}$ and $6 \mathrm{a}$ (inter-group $S$ value $=67 \%$ ), $6 \mathrm{a}$ and $4 \mathrm{a}$ (inter-group $S$ value $=67 \%$.

The strains of Staphylococcus aureus were not subjected to Adansonian analysis.

Table 3. Intra-group and inter-group $S$ values (\% similarity) for all strains used in this study

\begin{tabular}{|c|c|c|c|c|c|c|c|c|c|c|c|c|c|}
\hline & \multirow[b]{2}{*}{$\begin{array}{c}\text { Sub- } \\
\text { groups }\end{array}$} & \multicolumn{8}{|c|}{ Micrococcus } & \multicolumn{3}{|c|}{$\begin{array}{l}\text { Staphylo- } \\
\text { coccus }\end{array}$} & \multirow{2}{*}{ moles \% } \\
\hline & & $1 \mathrm{a}$ & $1 \mathrm{~b}$ & $2 a$ & $2 b$ & $2 \mathrm{c}$ & $3 a$ & $3 \mathrm{~b}$ & 3c & $4 \mathbf{a}$ & $5 a$ & $\overline{6 a}$ & \\
\hline \multirow{7}{*}{ Micrococcus } & $1 \mathbf{a}$ & 72 & & & & & & & & & & & \multirow{2}{*}{$70.8-73.3$} \\
\hline & $1 \mathrm{~b}$ & 59 & 73 & & & & & & & & & & \\
\hline & $2 \mathbf{a}$ & 56 & 56 & 67 & & & & & & & & & \multirow{3}{*}{$67.5-69.5$} \\
\hline & $2 b$ & 68 & 69 & 58 & $100^{*}$ & & & & & & & & \\
\hline & $2 \mathrm{c}$ & 50 & 42 & 39 & 50 & $100^{*}$ & & & & & & & \\
\hline & $3 \mathbf{a}$ & 64 & 67 & 56 & 66 & 48 & $100^{*}$ & & & & & & \multirow{3}{*}{$65.8-67.0$} \\
\hline & $3 \mathrm{~b}$ & 66 & 55 & 48 & 58 & 44 & 51 & $100^{*}$ & & & & & \\
\hline & $3 \mathrm{c}$ & 53 & 65 & 53 & 60 & 36 & 61 & 56 & $100^{*}$ & & & & \\
\hline \multirow{3}{*}{ Staphylococcus } & $4 a$ & 39 & 44 & 54 & 38 & 34 & 45 & 31 & 38 & $100^{*}$ & & & $54 \cdot 2$ \\
\hline & 5 a & 45 & 44 & 57 & 45 & 28 & 40 & 46 & 46 & 60 & $100^{*}$ & & $36 \cdot 4$ \\
\hline & $6 \mathbf{a}$ & 39 & 45 & 59 & 45 & 31 & 39 & 35 & 41 & 67 & 67 & 71 & $33.3-34.2$ \\
\hline
\end{tabular}

\section{DISCUSSION}

The genera Micrococcus and Staphylococcus. Drawing some general conclusions about the importance of DNA base composition for bacterial taxonomy, Sueoka (1961) pointed out that if the mean moles \% GC of the DNA's of two strains is different by $10 \%$ there will be few DNA molecules of the same GC content common to them. Such strains are certainly phylogenetically distant and they should be classified as members of different genera, if it were the aim to include in the same genus only species more or less phylogenetically related. For this reason, the whole set of strains split into two branches obviously representing two distinct genera. The first branch is formed of groups 1,2 and 3, i.e. strains with a GC content within the range $66 \cdot 3-\mathbf{7 3 \cdot 3}$ moles $\%$. The second branch is formed of groups 5,6 and 7, i.e. strains whose GC content ranges from $30 \cdot 7$ to $36 \cdot 4$ moles $\%$. The same division into two branches is confirmed by Adansonian analysis, because all the strains of groups 5, 6 and 7 show a low percentage of similarities with respect to the groups 1,2 and 3.

Silvestri \& Hill (1965) arrived at the conclusion that Gram-positive catalasepositive cocci with low GC moles \% values correspond to the genus Staphylococcus, while Gram-positive, catalase-positive cocci with high moles \% GC values correspond to the genus Micrococcus. As outlined by Baird-Parker $(1963,1965)$ organisms placed in the genus Staphylococcus are characterized by ability to grow and produce acid from glucose when incubated under anaerobic conditions in a mineral salts yeast-extract agar medium containing bromcresol purple as $\mathrm{pH}$ indicator. On the other hand the genus Micrococcus includes cocci which are either unable to produce sufficient acid from glucose to change the indicator brocresol purple or which grow and produce acid from glucose only in the presence of air. The anaerobic fermentation of glucose is, therefore, recommended as a test for distinguishing the genus 
Staphylococcus from Micrococcus (Subcommittee on Taxonomy of Staphylococci and Micrococci, 1965; Evans, 1965). Applying this test to the strains studied in this paper we have come to the following conclusions. (1) All the strains showing a high moles \% GC were unable to produce acid from glucose under anaerobic conditions. Most strains did not produce any detectable acid from glucose under aerobic conditions. Only some of them produced acid from glucose when grown aerobically (strains of subgroup 2a). (2) The strains (group 7, subgroup 5a) with low values of moles GC content were able to produce acid from glucose anaerobically, while the others (subgroup 6a) only did so aerobically. On the basis of these results the following conclusions may be drawn.

Species of the genus Staphylococcus have a GC content within the range 30.736.4 moles \%. All the Gram-positive cocci so far designated as micrococci and sarcinas which produce acid from glucose when grown under anaerobic or aerobic conditions and which have a GC content within this range should be also classified as Staphylococcus. On the other hand species of the genus Micrococcus have a GC content within the range 66.3-73.3 moles $\%$. All the Gram-positive cocci hitherto designated as sarcinas and staphylococci which do not produce acid from glucose under aerobic and anaerobic conditions or only aerobically, and which have a GC content in DNA within this range, should be also classified as Micrococcus.

The range of GC content as outlined for the genera Staphylococcus and Micrococcus is only approximate. It will be made more accurate (perhaps a little broader) when more data are available on the DNA base composition of the species belonging to the family Micrococcaceae.

\section{Classification of micrococci}

In our opinion it is at present premature to classify micrococci into species until their physiology, biochemistry and DNA base composition are better known. It would be more convenient and less influenced by subjective speculations if for the time being taxonomists aimed to detect among the micrococci natural groups that were clearly defined physiologically as well as biochemically. Such an attempt to classify micrococci has been made by Hill (1959), Pohja \& Gyllenberg (1962) and Baird-Parker $(1963,1965)$. On the basis of DNA base composition the micrococci we have studied may be divided into the following groups and subgroups.

Group 1. This group comprises strains with a GC content within the range $70 \cdot 8-73 \cdot 3 \%$. It consists of two subgroups.

Subgroup $1 a$ is formed mostly of yellow pigmented organisms. Some strains are able to produce both yellow and violet pigments. These strains give yellow pigmented spontaneous mutants which have lost their ability to produce violet pigment and in some media they overgrow the parent culture (Rosypal et al. 1963). Thus, the ability to produce yellow pigment appears to be chacteristic of all the strains of this subgroup. Non-pigmented strains are exceptions (rare mutants). According to Kocur \& Martinec (1962) all the strains included in subgroup 1 a do not release detectable acid when grown in peptone water with glucose or other carbohydrates. Results obtained by Baird-Parker $(1963,1965)$ would indicate that the latter strains can, at least some of them, produce acid when grown in a mineral salts yeast-extract medium containing glucose. In comparison with other subgroups the ability to hydrolyze gelatin and the inability to oxidize mannitol in phosphate buffer at $\mathrm{pH} 7$ may be of some importance for identification of this subgroup. 
Considering all the above physiological characteristics, this subgroup 1a appears to correspond to Baird-Parker's Micrococcus subgroup 7 (Baird-Parker, 1965). According to Kocur \& Martinec (1962) all strains included in subgroup 1a are considered to be identical with Micrococcus luteus. However, the type strain $\boldsymbol{M}$. luteus ATCC 398 has a GC content different from that of all the strains of subgroup 1 a (see also Rosypalová et al. $1966 a, b$ ). Since the name designation of the type species should not be changed, the name of this subgroup appears to be questionable for the time being.

Subgroup $1 b$ is formed only of pink-pigmented micrococci, which are taxonomically well described. They obviously correspond to Baird-Parker's Micrococcus subgroup 8 and to the species named Micrococcus roseus (Evans, 1965; Baird-Parker, 1965; Kocur \& Martinec, 1962). None of the strains belonging to this subgroup hydrolyze gelatin, but they reduce nitrates and oxidize mannitol and sorbitol in phosphate buffer at $\mathrm{pH} 7$. They are not able to produce acid from glucose in peptone water.

Group 2. The strains belonging to this group have a GC content within the range 67.5-69.5 moles $\%$. The following three subgroups are known:

Subgroup $2 a$ is formed of yellow-pigmented strains. In contrast to other yellowpigmented cocci they release acid from glucose when grown under aerobic conditions, but no acid is formed when they are incubated anaerobically; they oxidize sorbitol in phosphate buffer at $\mathrm{pH}$ 7. By these physiological characters they can be well distinguished from the other subgroups; they correspond to Baird-Parker's Micrococcus subgroups 5 and 6 . As can be seen from Table 1 and Fig. 2 we included in subgroup 2a the strains which are considered by Kocur \& Martinec (1962) as Micrococcus conglomeratus and $M$. varians.

Subgroup $2 b$. This is a yellow-pigmented strain which does not hydrolyze gelatin; in its other characteristics it resembles the strains of subgroup 1a. The similarity of this strain to the strains of subgroup 1a is evident from Fig. 2. The considerable physiological and biochemical similarity of this strain to the organisms of subgroup 1 a has resulted in it being considered by Kocur \& Martinec (1962) to be identical with the strains of subgroup $1 \mathrm{a}$. The DNA base composition is significantly different from the strains of subgroup $1 \mathrm{a}$, however, and place it in a separate group.

Subgroup $2 c$. This yellow pigmented strain differs from the strains of subgroup 1 a not only in its DNA base composition, but also physiologically and biochemically; see the Adansonian analysis cf. Fig. 2.

Group 3. This group comprises strains with a GC content within the range 66.3-67.0 moles $\%$. The species Micrococcus denitrificans is not included in this group. Therefore it consists of two subgroups:

Subgroup $3 a$. This is a violet pigmented coccus not producing a yellow pigment. Although having high $S$ values with most strains of subgroup 1 a, it differs from them by its DNA base composition and by ability to oxidize mannitol and dulcitol (Rosypalová \& Rosypal, 1966; Rosypalová et al. 1966a, b).

Subgroup 3b. Micrococcus luteus, type species, ATCC 398. It has a GC content quite different from the strains of subgroup 1 a and cannot be considered identical with them, as believed by Kocur \& Martinec (1962). Its classification with the strains of subgroup 1 a resulted from its showing some physiological and biochemical similarity to these strains.

'Subgroup 3c' formed of Micrococcus denitrificans is questionable. Baird-Parker 
(1965) suggests that it should be reclassified with the Gram-negative genera and gives the following reasons for it: (1) it is Gram-negative and forms rods in young cultures, (2) it has a cell-wall mucopeptide which contains a wide range of amino acids characteristic of Gram-negative genera. For these reasons Micrococcus denitrificans cannot be included in the genus Micrococcus even if it has a similar GC content to that of other members of group 3. We must, therefore, correct the opinion of Rosypalová et al. (1966b), where this species was considered to be closely related to $M$. luteus. On the basis of the above-mentioned facts it shows no phylogenetical relationship to species of the genus Micrococcus.

\section{Classification of staphylococci}

It is not the aim of the present paper to deal fully with the classification of staphylococci. We touch upon this question only as it concerns the strains originally classified as micrococci and now classified as staphylococci. On the basis of DNA base composition we divided these strains into three groups. Group 5 is represented by one strain (subgroup 5a) having $\mathbf{3 6} \cdot 4$ moles \% GC. It is the strain Micrococcus cerolyticus, ATcc, 12559. Baird-Parker (1965) included it in his Staphylococcus subgroup V. It produces acid from glucose when grown under anaerobic conditions. Group 6 consists of subgroup 6 a, i.e. strains with a GC content 33·3-34.2 moles \%. Since these strains produce acid from glucose only when grown under aerobic conditions, they have been so far classified as micrococci (M. varians). Their GC content places them, however, in the genus Staphylococcus.

Group 7 is formed of subgroup 7 a and corresponds to the species Staphylococcus aureus (Baird-Parker's Staphylococcus subgroup I), whose GC content has been found to be 30.7 to 32.7 moles $\%$. On the whole, it may be said that the range of GC content in DNA of the strains belonging to the genus Staphylococcus is so large that it will comprise more than the two species, so far recognizable, Staphylococcus aureus and $S$. epidermidis. This is also suggested by Baird-Parker's classification, in which staphylococci are divided into six subgroups (Baird-Parker, 1963, 1965). Group 4 is formed of subgroup 4 a represented by a strain with $\mathbf{5 6 \cdot 4}$ moles \% GC. It deserves particular attention because its DNA base composition is quite unlike that which has been found with the genera Micrococcus and Staphylococcus. It produces acid from glucose only when grown under aerobic conditions and is sensitive to several staphylococcal phages, but in DNA base composition it differs from both Staphylococcus and Micrococcus.

\section{REFERENCES}

Baird-Parker, A. C. (1963). A classification of micrococci and staphylococci based on physiological and biochemical tests. J. gen. Microbiol. 30, 409.

Baird-Parker, A. C. (1965). The classification of staphylococi and micrococci from world-wide sources. J. gen. Microbiol. 38, 363.

Evans, J. B. (1965). Current views and problems relating to the taxonomy of the Micrococcaceae. Int. Bull. bact. Nomencl. Taxon. 15, 111.

Hill, L. R. (1959). The Adansonian classification of the staphylococci. J. gen. Microbiol. 20, 277 .

Kocur, M. \& Martinec, T. (1962). Taxonomic study of the genus Micrococcus. Folia Prírod. fakulty UJEP, 3. 
Pohja, M. S. \& Gyllenberg, N. G. 1962. Numerical taxonomy of micrococci of fermented meat origin. $J$. appl. Bact. 25, 341.

Rosypal, S., Boháčex, J. \& Rosypalová, A. (1966). DNA base composition of Micrococcus varians. Publ. Fac. Sci. Univ. J. E. Purkyné. No. 471, 115.

Rosypal, S. \& Kocur, M. (1963). The taxonomic significance of the oxidation of carbon compounds by different strains of Micrococcus luteus. Antonie van Leeureenhoek, 29, 313.

Rosypal, S., Kocur, M. \& Hoňák, K. (1963). A study of violet-pigmented micrococci. Yellow-pigmented mutants of Staphylococcus flavocyaneus. J. gen. Microbiol. 32, 189.

Rosypal, S. \& Rosypaloví, A. (1966). A comment to the definition of the genera Micrococcus and Staphylococcus. Publ. Fac. Sci. Univ. J. E. Purkynĕ. No. 471, 105.

Rosypalová, A., Boháček, J. \& Rosypal, S. (1966a). Deoxyribonucleic acid base composition of violet cocci. Antonie van Leeurenhoek, 32, 105.

Rosypalová, A., Boháček, J. \& Rosypal, S. (1966b). Deoxyribonucleic acid base composition of some micrococci and sarcinae. Antonie van Leeuroenhoek, 32. (in press).

Rosypalová, A. \& Rosypal, S. (1966). Some physiological properties of violet-pigmented micrococci. Their oxidation pattern and ability to grow in minimal synthetic medium. Publ. Fac. Sci. Univ. J. E. Purkyně. (in press).

Silvestri, L. G. \& Hill, L. R. (1965). Agreement between deoxyribonucleic acid base composition and taxometric classification of Gram-positive cocci. J. Bact. 90, 136.

SNEATH, P. H. A. 1957. The application of computers to taxonomy. J. gen. Microbiol. 17, 201.

Subcommittee on Taxonomy of Staphylococci and Micrococci (1965). Recommendations. Int. Bull bact. Nomencl. Taxon. 15, 109.

SUEOKA, N. (1961). Variation and heterogeneity of base composition of deoxyribonucleic acids: compilation of old and new data. J. mol. Biol. 3, 31. 